\title{
Regimes de verdade, regimes de governamentalidade: uma análise foucaultiana sobre o Estatuto da Família
}

\author{
Esmael Alves de Oliveira ${ }^{1}$ \\ Simone Becker ${ }^{2}$ \\ Universidade Federal da Grande Dourados
}

Resumo: O presente artigo visa refletir sobre alguns pressupostos presentes no Projeto de Lei (PL) 6583/2013, de autoria do deputado Anderson Ferreira, do $\mathrm{PR} / \mathrm{PE}$, e que ficou conhecido como Estatuto da Família. Tomando como inspiração as reflexões de Michel Foucault acerca da biopolítica, desejamos apontar, a partir de uma análise do discurso, de que modo se constroem narrativas que pretendem uma verdade sobre grupos minoritários e suas práticas, sobre "homens" e "coisas" (FOUCAULT, 2007a, 2008). Afinal, como a biopolítica atualizada no século XXI segue operando tanto na constituição de sujeitos coletivos quanto na elaboração de subjetividades senão a partir de um biopoder sobre o corpo, sobre a vida e que se assegura justamente por uma discursividade que se pretende transparente e ideologicamente "desinteressada"? Portanto, ao nos debruçarmos sobre os dispositivos biopolíticos presentes no referido PL, buscamos encarar limites, contradições e arbitrariedades de um regime de verdade que, pautado em noções de direito e cidadania, tende a desqualificar, invisibilizar e deslegitimar determinados grupos, sujeitos, corpos, práticas e relações.

Palavras-chave: Estatuto da família, Conjugalidades, Biopolítica, Foucault. 


\title{
Regimes of truth, governmentality regimes: a foucaultian analysis of the Family Statute
}

\begin{abstract}
This article aims to reflect on some of the assumptions present in Bill 6583/2013, authored by representative Anderson Ferreira, of PR/PE, which became known as the Family Statute. Taking Michel Foucault's reflections on biopolitics as an inspiration, we wish to point out, from an analysis of the discourse, how narratives are built that claim a truth about minority groups and their practices, about "men" and "things" (FOUCAULT, 2007b; 2008). After all, how the updated biopolitics of the 21st century continue to operate both in the constitution of collective subjects and in the elaboration of subjectivities, but rather through biopower over the body, over life and that is ensured precisely by a discursivity that is intended transparently and ideologically "disinterested"? Therefore, when we look at the biopolitical devices present in this PL, we seek to face the limits, contradictions and arbitrariness of a truth regime that, based on notions of law and citizenship, tends to disqualify, make invisible and delegitimize certain groups, subjects, bodies, practices and relations.
\end{abstract}

Keywords: Family Statute, Conjugalities, Biopolitics, Foucault.

\section{Regímenes de verdad, regímenes de gobierno: un análisis foucaultiana sobre el Estatuto de la Familia}

\begin{abstract}
Resumen: El presente artículo pretende reflexionar sobre algunos presupuestos presentes en el Proyecto de Ley (PL) 6583/2013, de autoría del diputado Anderson Ferreira, del PR / PE, y que se conoció como Estatuto de la Familia. Tomando como inspiración las reflexiones de Michel Foucault acerca de la biopolítica, deseamos apuntar, a partir de un análisis del discurso, de qué modo se construyen narraciones que pretenden una verdad sobre grupos minoritarios y sus prácticas, sobre "hombres" y "cosas" (FOUCAULT, 2007a, 2008). Al final, como la biopolítica actualizada en el siglo XXI sigue operando tanto en la constitución de sujetos colectivos como en la elaboración de subjetividades sino a partir de un biopoder sobre el cuerpo, sobre la vida y que se asegura justamente por una discursividad que se pretende transparente e ideológicamente " desinteresado "? Por lo tanto, al ocuparnos de los dispositivos biopolíticos presentes en el referido PL, buscamos encarar límites, contradicciones y arbitrariedades de un régimen de verdad que, pautado en nociones de derecho y ciudadanía, tiende a descalificar, invisibilizar y deslegitimar determinados grupos, sujetos, cuerpos, prácticas y relaciones.
\end{abstract}

Palabras clave: Estatuto de la familia, Conjugalidades, Biopolítica, Foucault. 
$\mathrm{O}$ presente artigo visa refletir sobre alguns pressupostos presentes no projeto de lei (PL) 6583/2013, de autoria do deputado Anderson Ferreira, do PR/PE, e que ficou conhecido como Estatuto da Família. Tomando como base as reflexões de Michel Foucault acerca da biopolítica, pretendemos apontar, a partir de uma análise do discurso, de que modo se constroem táticas discursivas que objetivam uma verdade sobre grupos minoritários e suas práticas. Como o biopoder opera tanto na constituição de sujeitos quanto na elaboração de subjetividades senão a partir de uma biopolítica sobre homens e coisas? Portanto, ao nos voltarmos para os dispositivos biopolíticos que gerenciam corpos e vidas, buscamos evidenciar limites, contradições e arbitrariedades de um regime de verdade que, pautado em noções de direito e cidadania, tende a desqualificar, invisibilizar e deslegitimar determinados grupos e seus estilos de vida.

Michel Foucault, em diferentes trabalhos (2007a, 2008), traça um panorama de como se constituiu na Idade Clássica, a partir do século XVIII, uma série de saberes que visavam ao controle sobre a vida: um poder soberano, centrado na figura do rei, de seu poder absoluto e sob uma prática centrada na pastoral da confissão. Aos poucos, em decorrência de transformações de ordem político-econômica, ergue-se uma economia política sobre a vida, ou, nas palavras de Foucault (2007a; 2008), uma governamentalidade. Cabe notar que, de uma massa informe, como era a noção de povo, cria-se uma categoria censitária que busca dar conta do conglomerado humano, a fim de melhor controlá-lo a partir do dispositivo estatístico: a população. Nesse quadro, seria necessário saber, além do número de cidadãos existentes em um determinado território, também a quantidade de nascimentos, mortes, doentes e todo um conjunto de dados quantitativos que poderiam contribuir para a administração dos grupos. Conforme Didier Fassin, “'Biopoder' não é exatamente o poder sobre a vida em oposição ao direito soberano de morte [...], mas o poder sobre a conduta humana: 'o governo dos vivos' refere-se sobretudo à normalização dos indivíduos através de tecnologias políticas" (2009, p.45-46).

Quando nos debruçamos sobre o Projeto de Lei 6583/2013, as considerações de Foucault (ano) sobre biopoder mostram-se relevantes à medida que nos ajudam a destrinchar as tessituras político-ideológicas que ajudam a constituir tal aparato legal-normativo, possibilitando-nos a desnaturalização de categorias e pressupostos nele presentes, que apontam para uma vontade de verdade sobre grupos, seus corpos e suas vidas. Aliás, as desconstruções das representações e das interpretações, que tendem às (re)produções de violências (BUTLER, 20043), tornam-se mais viáveis quando sacamos, de nossas mangas, as cartas

3 Em "Le pouvoir des mots" (O poder das palavras), a filósofa trará a noção de "atos ilocutórios", o que aqui nos inspira a pensarmos nelas como instituidoras de práticas judiciais, incluindo a própria agenda de projetos de leis conservadores e disparadores da homogeneização de categorias sociais, como aqueles que concebem a família de maneira única e imutável. Essas questões, ao longo do presente artigo, serão retomadas. O ato ilocutório é aquele que, ao ser enunciado, 
("mágicas") a nós ofertadas pela filosofia da diferença. Dentre elas, a lógica pautada na multiplicidade/perspectivismo nietzschiano que alimenta as noções de teóricxs4 como Foucault, Félix Guattari e Gilles Deleuze. Estes, por sua vez, inspiram com capilaridades, rizomas, devires, molares e moleculares as (des)pensações de Judith Butler, Marylin Strathern, Roy Wagner e Paul Beatriz Preciado, dentre outros.

Vejamos as contribuições que Eduardo Viveiros de Castro (2015, p. 111112) produz rumo a essa toada de privilegiarmos a experimentação por meio do interagir em detrimento da representação pelo interpretar:

[...] Assiste-se ao colapso, na verdade, da distinção entre epistemologia (linguagem) e ontologia (mundo), e à progressiva emergência de uma "ontologia prática" (JENSEN, 2004) dentro da qual o conhecer não é mais um modo de representar o desconhecido, mas de interagir com ele, isto é, um modo de criar antes que um modo de contemplar, de refletir ou de comunicar (D.\&G., 1991). A tarefa do conhecimento deixa de ser a de unificar o diverso sob a representação, passando a ser a "de multiplicar o número de agências que povoam o mundo" (LATOUR, 1996). Os harmônicos deleuzianos são audíveis. Uma nova imagem do pensamento. Nomadologia. Multinaturalismo (destaques no original).

A partir dessas considerações, perguntamo-nxs: no PL 6583/2013, o que está em cena senão uma compreensão naturalizada e essencialista dos sujeitos e de suas práticas que visa não apenas a sua deslegitimação, mas, sobretudo , ao estabelecimento de vidas matáveis e não choráveis? (BUTLER, 2015). Aliás, vidas convenientemente "essencializadas" pela "onda conservadora" da "bancada" e/ou "frente parlamentar" evangélica em nosso Congresso Nacional (ALMEIDA, 2017), que se espraia e se entrelaça a outras bancadas, como a ruralista (MACEDO, 2017). Não por acaso, atualmente, opera-se um deslocamento analítico da noção de biopolítica para a de necropolítica, por meio da qual podemos perceber diferentes mecanismos que dos Estados contemporâneos (e o Brasil não é exceção) se utilizam para cada vez mais se aprimorarem e se apropriarem do direito de matar, este como expressão de sua soberania (MBEMBE, 2006).

Percebamos o quanto um transpartidarismo faz com que as temáticas de gênero, sexualidade, raça, classe e etnia, por exemplo, misturem-se em meio a defesas de projetos de parlamentares membros das bancada evangélica e ruralista, que podem ser os mesmos, considerando-se a capilaridade entre as bancadas e/ou frentes parlamentares5. Sigamos as costuras tecidas por Ronaldo de Almeida (2017, s/p) em artigo que cartografa a bancada evangélica e seus sentidos em forma de projetos:

Se no nível individual o discurso religioso procurar gerar disposição para o empreendedorismo, no plano da política institucional, muitos agentes políticos evangélicos militam declaradamente por uma agenda liberal. Na campanha presidencial de 2014 , o candidato Pastor Everaldo, com 0,75\% dos votos, fez o discurso que combina menor presença do Estado na economia e mais regulação jurídica da moralidade pública. O então presidente da Câmara dos Deputados, Eduardo Cunha, foi protagonista na aprovação, em primeira instância, do Projeto das Terceirizações, que contou com o voto da Frente Parlamentar Evangélica. Ou, ainda, vale citar a disputa do PSC pela FUNAI, órgão federal central no processo de demarcação de terras

já produz efeitos de imediato para além do papel e à revelia de resistências por parte dx destinatárix. Em suma, os atos ilocutórios particularizam os discursos sentenciais como exemplares.

4 Por vezes, usaremos o "x" ao invés de "a" ou "o". O "xis" substitui os marcadores que sinalizam na língua portuguesa os correspondentes de gênero para os universais masculinos ou femininos em pronomes e artigos. Isso porque se considera que a verdade de nós, sujeitos, está no nosso "sexo" definido com pré(cisão) pela biomedicina e pela lei "a la" Foucault (2007b).

5 As Frentes Parlamentares são grupos formais criados junto ao Congresso Nacional (CN), responsáveis por defender causas/temáticas que unem parlamentares e respectivos partidos políticos. Por exemplo, as questões religiosas marcam o agir da Frente Parlamentar Evangélica, cujos membros são de diferentes partidos. Ademais, há outras quatro relevantes Frentes Parlamentares: empreiteiras/construtoras; parentes/ruralista e de empresários (MACEDO, 2017). 
indígenas e quilombolas. Na CPI da FUNAI-INCRA, na Câmara dos Deputados, a Frente Parlamentar Evangélica operou como linha auxiliar da denominada bancada do agronegócio e da mineração em oposição aos que milita pelos direitos dos indígenas, sobretudo, à terra. (grifos nossos) ${ }^{6}$

Além disso, em que medida, buscando-se pautar em um discurso de "garantia" de direitos, o PL tem justamente o efeito contrário, ou seja, de se constituir como um dispositivo de legitimação da desigualdade e da negação de direitos de cidadania? (OLIVEIRA; DUQUE, 2016). Para fins de análise, destacamos e problematizamos alguns fragmentos do referido dispositivo legal.

Em seu Art. $2^{\circ}$, deparamo-nos com a seguinte definição de família: "para os fins desta Lei, define-se entidade familiar como o núcleo social formado a partir da união entre um homem e uma mulher, por meio de casamento ou união estável, ou ainda por comunidade formada por qualquer dos pais e seus descendentes" (CÂMARA DOS DEPUTADOS, 2018a, s/p). Note-se que o destaque em negrito está no texto original e tem o intuito de demarcar a compreensão levada à cabo pelo agente que elaborou tal regulamento.

O que de imediato é possível verificar nessa definição de família? Em primeiro lugar, uma ideia naturalizada e restrita. Nesse aspecto, é negado o reconhecimento de arranjos familiares que não correspondam ao modelo heterossexual. Como ficam os casos de homossexuais que adotam crianças? De famílias constituídas por avós que se apresentam como cuidadores e provedores? E das mães solteiras? Diante da definição apresentada pelo PL, esses "novos" arranjos familiares, além de não serem reconhecidos, possibilitam que seus direitos de cidadania sejam negados, principalmente em se tratando de famílias homoparentais. É o que podemos depreender a partir do Art. $3^{\circ}$ : "é obrigação do Estado, da sociedade e do Poder Público em todos os níveis assegurar à entidade familiar a efetivação do direito à saúde, à alimentação, à educação, à cultura, ao esporte, ao lazer, ao trabalho, à cidadania e à convivência comunitária" [grifos nossos].

Em outras palavras, por não serem reconhecidas como núcleos familiares, as famílias homoparentais, ou cujos arranjos fujam ao convencional, poderiam ter seus direitos básicos negados, como por exemplo à pensão por morte, INSS, licença maternidade, etc, já que não corresponderiam ao critério estabelecido pelo dispositivo legal. Em cena, apenas a família engendrada pelo regime de uma governamentalidade que estabelece quais homens e "coisas" (FOUCAULT, $2007 \mathrm{~b}$; 2008) vale, importa. Assim, observamos nesse discurso uma representação de papéis de gênero tal como normatizado pela sociedade heteronormativa, em que homens e mulheres possuem não apenas identidades fixas, mas também papéis/funções correspondentes e que devem ser “preservados” por um Estado policialesco e discriminatório.

Não seria errôneo afirmar, pois, que os que propõem tal projeto de lei são os mesmos que tendem a justificar a subalternidade feminina no espaço social e privado e que tendem a enquadrá-la como associada e determinada à natureza e, consequentemente, à maternidade, ao cuidado do marido, da casa e dos filhos. Essa conjectura que beira ao lúdico de um ridículo se faz interessante para nos atentarmos à onda "quebrada" e conservadora, parafraseando Ronaldo de Almeida (2017), que reveste o PL em questão, mas também os pontos de toque das violências que prevalecem nos vários Brasis, a saber: contra os corpos femi-

${ }^{6}$ Disponível em: http://www.scielo.br/pdf/cpa/n50/1809-4449-cpa-18094449201700500001.pdf. Acesso em: 15 ago. 
ninos (não) passíveis de atenção e, muito menos, de luto (BUTLER, 2015; BECKER; OLIVEIRA; CAMPOS, 2016).

Esse cenário legal-normativo, essencial-generificado, ajuda-nos a pensar sobre os quadros de violência contra mulheres e suas omissões e reiterações. A maioria dos feminicídios contra corpos de bio/cis mulheres tende a ser protagonizada por familiar/parceiro dentro de um arranjo heteronormativo. Os transfeminicídios, por sua vez, dão-se pela relação que perpassa também a prostituição, cujas tessituras imbricam-se com a economia das trocas conjugais, como nos inspira a pensar Virginie Despentes (2013).

Em recente e inédito dossiê sobre os lesbocídios no Brasil de 2014-2017 (PERES, 2018), as engrenagens da necropolítica (MBEMBE, 2016) do Estado brasileiro contra os corpos femininos apontam para o quanto homens que matam lésbicas manifestam um ódio descontrolado contra corpos e desejos que destoam das normas de gênero. Assim, nota-se como características que são essencializadas/essencializadoras sobre o que é "ser homem ou ser mulher" instituem-se como disparadores de ódios e violências que pululam no pós-golpe de 2016 - travestido de impeachment contra a então presidenta Dilma Rousseff, ela própria alvejada por disparos de discursos racistas, lesbofóbicos, misóginos, homofóbicos e preconceituosos face às suas performances. Trata-se de discursos reiteradores do feminino como respública, coisa pública e então direito dos homens.

Nesse sentido, as diferenças são estabelecidas "na carne" e impossibilitam que os sujeitos possam se desvencilhar de uma determinada "identidade", haja vista que suas diferenças estão solidamente ancoradas em bases políticoepistemológicas neutralizadoras e patologizadoras de dissidências. No modelo dimórfico, inaugurado pelo discurso moderno, o gênero aparece colado ao sexo, criando uma barreira quase intransponível entre homem e mulher (LAQUEUR, 2001) 7 .

Nessa seara, cabe resgatarmos discussões que permeiam férteis convicções do discurso antropológico brasileiro no tocante às celeumas provocadas por posturas perversas e conservadoras de nosso Poder Legislativo. Em nota pública tecida por Flávio Tarnovski (2016, p. 03-04) junto ao informativo especial da Associação Brasileira de Antropologia, lê-se que:

\begin{abstract}
As pesquisas antropológicas sobre parentesco indicam que a ideia de compartilhamento de uma mesma substância pode ser uma representação social importante na esfera das relações de parentesco, mas o fundamento dessas relações é sempre social. As relações eletivas, marcadas pela afetividade, também estão presentes nas relações de parentesco baseadas na biologia. No entanto, as relações familiares que não se apoiam em uma representação simbólica do "mesmo sangue" não são, por essa razão, menos importantes e dignas de reconhecimento pelo Estado.
\end{abstract}

Algumas palavras-chave, noções e categorias presentes no PL em análise são paradigmáticas e muito revelam sobre os princípios ideológicos que o norteiam. No artigo Art. $4^{\circ}$, inciso IX, por exemplo, estipula-se que, dentre as funções dos agentes públicos ou privados, está a de "zelar pelos direitos da entidade familiar" (CÂMARA DOS DEPUTADOS, 2018a, s/p, grifos nossos). Como afirma Foucault (1999, p. 10):

[...] O discurso [...] não é simplesmente aquilo que manifesta (ou oculta) o desejo; é, também, aquilo que é o objeto do desejo; e visto que [...] o discurso não é simples-

7 Não ao acaso, os crimes contra travestis se pautam pela ojeriza que o reconhecimento do desejo por quem porta e sustenta a concomitância do ser homem e ser mulher causa. Para maiores informações sobre a situação no Mato Grosso do Sul entre judiciário e travestis, ver Simone Becker e Hisadora G. Lemes (2014). 
mente aquilo que traduz as lutas ou os sistemas de dominação, mas aquilo por que, pelo que se luta, o poder do qual nos queremos apoderar [...].

Desse modo, podemos nos perguntar: o que é zelar? Quem zela? Por que zela? Com quais finalidades/interesses? Quem estabelece os critérios desse zelar? Quais as implicações disso? Assim, sob uma biopolítica de governamentalidade, pela qual governar é administrar "homens" e coisas (e por que não dizer, práticas?), a família (ou melhor, o que se entende como tal) é o lócus privilegiado do exercício da governança. Ela (embora não apenas) torna-se alvo por excelência da vigilância e do escrutínio de uma gestão de legalismos generificantes.

As contradições continuam. Em seu Art. $6^{\circ}$, inciso I, prevê-se o: "cadastramento da entidade familiar em base territorial” (grifos nossos). Também no Art. $12^{\circ}$, lê-se: "as escolas deverão formular e implantar medidas de valorização da família no ambiente escolar, com a divulgação anual de relatório que especifique a relação dos escolares com as suas famílias" " (grifos nossos). Como não lembrar, nos termos foucaultianos, que a ciência da "polícia" é a estatística? (FOUCAULT, 2007b).

Se, como afirma Foucault, a partir do século XVIII, com a crise do poder soberano, busca-se o estabelecimento de princípios de uma arte de governar pautada, sobretudo, em procedimentos de "[...] como se governar, como ser governados, como fazer para ser o melhor governante possível" (FOUCAULT, 2007b, p. 277-278), há que se pensar também sobre "o problema de como ser governado, por quem, até que ponto, com qual objetivo, com que método, etc." (FOUCAULT, 2007b, p. 278). Dito de outro modo, torna-se necessário percebermos a criação de estratégias biopolíticas que tanto privilegiem a administração dos sujeitos quanto a população. Portanto, em uma política sobre a vida, há que se registrar, catalogar, mapear, territorializar, esquadrinhar e quantificar sujeitos, corpos, comportamentos, grupos, populações o máximo possível, visando a um maior controle. Diante desse cenário, o aparato jurídico-policialesco mostra-se fundamental. Incluímos também nesse contexto o mecanismo midiático, que, juntamente ao parlamentar e ao jurídico, inspiradxs em Suely Rolnik (2018), a nosso ver, (re)produzem esse campo minado por "inconscientes coloniais capitalísticos" que se materializam em retrocessos conservadores como desse PL.

No Projeto de Lei 6583/2013, não são poucas as vezes em que tanto o "direito" quanto a "segurança pública" são mencionados. Em nosso entender, tais princípios deixam evidenciados a tentativa de judicialização e a criminalização de determinados arranjos familiares, bem como determinadas práticas sociais tidas como não inteligíveis e, portanto, abjetas.

Nessa tarefa de gestar a vida "desejável”, a educação também tem seu "lugar ao sol”. É assim que o Art. $10^{\circ}$ dispõe:

[...] Os currículos do ensino fundamental e médio devem ter em sua base nacional comum, como componente curricular obrigatório, a disciplina "Educação para família", a ser especificada, em cada sistema de ensino e estabelecimento escolar, de acordo com as características regionais e locais da sociedade, da cultura, da economia e da clientela [grifos nossos].

Recentemente em todo Brasil iniciou-se um movimento intitulado "Escola sem partido", com intensificação após o golpe de 2016, travestido de impeachment (CHECA, 2017; FERREIRA, 2018). Como bandeira de luta de tal organização, buscou-se a proibição de que professores "utilizem o espaço da sala de aula para propagar conteúdos insidiosos e doutrinar” os estudantes. Em cena, pôs-se 
a ideia de que docentes estariam utilizando o espaço da sala de aula para "desvirtuar" os valores dos estudantes e inculcar ideologias "perigosas e deturpadas”. Caso tal acusação tivesse algum fundamento, caberia-nos o seguinte questionamento: se é proibido utilizar o espaço da sala de aula para a disseminação de "ideologias", não seria um contrassenso a obrigatoriedade do ensino de uma “educação para a família”? Se o espaço da escola deve ser "neutro", como propõem os articuladores da Escola sem Partido, pelo PL não estaria se impondo um modelo de doutrinação e ajustamento dos sujeitos (tal como as acusações feitas aos professores)? Percebamos o paradoxo: o que justamente tal projeto "parece" evitar acaba por reiterar.

Portanto, é evidente que uma análise sobre o dispositivo legal em estudo não pode prescindir de uma compreensão mais ampla das redes e articulações que o sustentam e que ecoam também em projetos com o mesmo espectro heteronormativo, tal como a Escola sem Partido (OLIVEIRA; DUQUE, 2016). Em um quadro em que se busca a reiteração de um modelo sexista e homofóbico, os dispositivos educacionais passam a ser um campo em disputa, pois operariam em um projeto de doutrinação e naturalização do status estabelecido. Assim, almeja-se que a escola e os procedimentos pedagógico-educacionais, ao contrário do que afirmam os partidários de "uma escola sem partido", torne-se uma instituição de um partido só, de um modelo só, de uma família só. Nessa proposta monossêmica, a diferença torna-se sinônimo inquestionável de desigualdade. E o que dizer do "dia nacional de valorização da família" estipulado no artigo $13^{\circ}$ ?

Observa-se, portanto, o enviesamento da discussão pela qual se privilegiam determinados modelos em detrimento de outros. E não apenas isso, uma vez que, por meio de um discurso que se diz democrático e garantidor de direitos e de cidadania, tenta-se justamente o contrário, ou seja, estabelecer o reconhecimento da desigualdade, da negação de direitos e de sua violação, através da disseminação de inverdades pautadas no "pânico moral” (MISKOLCI, 2008).

Em outras palavras, difundem-se, pela estigmatização da categoria "gênero", vulgo "ideologia de gênero", ideias que desestabilizariam o império da normatização de padrões postos impostoramente como ideais na e da heteronormatividade e suas coerências entre sexo, desejo e gênero, já pontuadas por Judith Butler (2003a). Em nosso entender, trata-se de uma luta articulada em torno da definição legítima de cidadania em que ficam de fora sujeitos e grupos que não correspondam aos ideais de normatividade arbitrariamente estabelecidos.

Outro aspecto do PL que precisa ser considerado é a importância dada a alguns campos disciplinares que historicamente estiveram vinculados (pelo menos no modelo hegemônico) ao disciplinamento dos corpos e das práticas. Em vários trechos, ou menciona-se diretamente a psicologia e o serviço social ${ }^{8}$ ou se faz referência às suas técnicas e/ou práticas (por exemplo, atendimento psicossocial, assistência, prevenção, promoção, proteção e recuperação). Fica a pergunta: por que justamente a assistência social e a psicologia? Não estaria subjacente uma ideia de delinquência, anormalidade, desajuste, vulnerabilidade, patologia, etc.?

Se a partir de Foucault (ano), compreendemos que os processos de subjetivação são produto de dispositivos de disciplinamento de corpos e "almas", os saberes psi não podem ser analisados alheios a atravessamentos de relações de

${ }^{8}$ Vale ressaltar que não desconsideramos as transformações no interior dos campos disciplinares, bem como de suas respectivas práxis. Apenas pontuamos que o referido PL, ignorando tais mudanças históricas presentes no interior dos campos, tende a privilegiar modelos e propostas que vão na contramão dessas mudanças e que, por vezes, reiteram uma visão medicalizante e higienista do mundo social. 
saber-poder. Além disso, enquanto os dispositivos prisionais criam a figura do delinquente, os dispositivos psi dão vida ao sujeito "louco", ao que é considerado mentalmente incapaz. Sob uma lógica de produção de subjetividades inteligíveis, o limite entre a norma e o desvio, entre o desejável e o indesejável, entre o valorizável e o desprezível, precisa ser permanentemente demarcado. Para isso, técnicas e táticas de gestão e governança precisam ser criadas e administradas. Não é à toa, pois, que encontramos no Art. $15^{\circ}$, inciso I a referência à necessidade de criação de pequenos conselhos. Segundo o referido artigo, caberia a tal conselho, dentre outras coisas, "[...] encaminhar ao Ministério Público notícia de fato que constitua infração administrativa ou penal contra os direitos da família garantidos na legislação". Mas quem define o que é uma infração? A partir de quais critérios e interesses? O que está ameaçado? Por quê?

Quando nos encaminhamos para a justificativa do PL, em seus trechos finais, deparamo-nos com um conceito de família que encontra grande eco no imaginário socialmente estabelecido: a família como célula "mater" da sociedade. Conforme o PL:

A família é considerada o primeiro grupo humano organizado num sistema social, funcionando como uma espécie unidade-base da sociedade. Daí porque devemos conferir grande importância à família e às mudanças que a têm alterado a sua estrutura no decorrer do tempo [grifos nossos].

Em cena, vê-se a normalização que deliberadamente busca apagar os traços que revelam a historicidade do dispositivo normalizador e que, desse modo, acaba por "denunciar" sua performatividade. Assim, se de um lado a família aparece como "base" essencial e inquestionável, ao mesmo tempo reconhece suas mudanças. Isso não impede que os idealizadores do referido projeto lutem pela manutenção e pela permanência dessa concepção, ainda que tal desejo/intuito seja irrealizável, afinal, "mudanças a têm alterado". Diante do impasse estabelecido, só resta jogar com a idealização. Assim, a norma é subvertida e o modelo esgarçado, a lei, o controle e a violência (não necessariamente física) buscam-se fazer impor a qualquer custo. Nesse quadro, ao ignorar a dimensão agonística e tensionamente da vida e das relações humanas e as contradições socialmente existentes e operantes, emerge um ideal de família cuja noção de equilíbrio torna-se central: "uma família equilibrada, de autoestima valorizada e assistida pelo Estado é sinônimo de uma sociedade mais fraterna e também mais feliz" [grifos nossos]. Se não bastasse essa compreensão, essa família idílica, por si só, seria responsável pela panaceia universal.

Igualmente, expressões como "na minha opinião", "crença" e "acredito" evidenciam mais uma vez o caráter ideologicamente enviesado da proposta e o senso comum que norteia tal projeto. Além disso, quando constatamos que a articulação em torno desse PL tem sido orquestrada principalmente pela bancada cristã da Câmara, ficam ainda mais explícitos os reais interesses dessa iniciativa: a manutenção de um modelo de família cristão, patriarcal e heteronormativo, que em outras palavras é sinônimo de patriarcal, monogâmico e heterossexual.

\section{Um(ns) discurso(s), outros ecos}

Na obra "A ordem do discurso", aula proferida por Michel Foucault no College de France, em 1970, o filósofo afirma que o discurso não é transparente nem neutro. Pelo contrário, como um dispositivo de poder, é constituído e atra- 
vessado por procedimentos internos e externos. Estes funcionariam como princípios organizadores que buscam dissimular intencionalidades e materialidades do discurso. Nas palavras do autor:

[...] Suponho que em toda sociedade a produção do discurso é ao mesmo tempo controlada, selecionada, organizada e redistribuída por certo número de procedimentos que tem por função conjurar seus poderes e perigos, dominar seu acontecimento aleatório, esquivar sua pesada e temível materialidade (FOUCAULT, 1999, p. 08-09).

Para Foucault (1999), na luta pela constituição de um discurso hegemônico e de verdade, operam princípios de exclusão, como a interdição e a oposição entre razão e loucura e entre verdadeiro e falso. Desse modo, quando nos voltamos para o PL 6583, com todo o "peso" jurídico-normativo que lhe é atribuído, e nos deparamos com uma determinada definição de família, com as obrigações do Estado com relação a ela e com os direitos que lhe são reconhecidos, vê-se, sobretudo, a construção de um ente de direitos que surge face à exclusão de seu outro-simétrico-oposto. Assim, ao estabelecer os princípios definidores de um arranjo familiar inteligível e desejável, seu contrário é instituído pela exclusão: não é, não existe, não tem direitos. Nessa tessitura de exclusão das diferenças, nenhum elemento discursivo é fortuito: se o sujeito é produto de relações de poder (FOUCAULT, 1995), ao tentar estabelecer, circunscrever, tipificar, marcar, enquadrar, que sujeito está sendo produzido? A mesma mecânica apontada por Foucault (1999) com relação aos princípios de exclusão é operada no PL no sentido de que o que parece importar é não apenas a luta pela definição legítima, mas principalmente do que é legítimo ou não, humano ou não, 9 o que importa ou não. Nessa lógica da afirmação pela exclusão, existiriam categorias de sujeitos que social e institucionalmente são consideradas como menos sujeitos do que outros (BECKER; OLIVEIRA, 2016). Mais do que isso, são enquadrados na condição de não sujeitos.

Essa não é uma tática nova. Como antes suscitado a respeito da multiplicidade de famílias que as mais diversas sociedades e seus agentes vivenciam, publicizada por meio do informativo da Associação Brasileira de Antropologia (TARNOVSKI, 2016), cabe trazermos as discussões suscitadas por Luiz Mello e Roger Raupp Rios. Luiz Mello (2006), em sua pesquisa clássica sobre a análise discursiva do trâmite do Projeto de Lei 1151/95 junto ao nosso legislativo brasileiro, discute que, desde 2005, há um vazio quanto ao amparo legal deconjugalidades que não sejam as heteronormativas. Se Mello acentua em seus escritos a negação de cidadania para pessoas homossexuais em suas vivências eróticas, a emergência da homossexualidade nos parece se dar como denúncia de uma sociedade brasileira guiada pelo princípio da igualdade (constitucional) e pautada na antidiscriminação, ao invés de o ser pelo viés da anti-subjugação. Acompanhemos como se dá essa tessitura proposta por Roger Raupp Rios sobre o princípio da igualdade com o norte da anti-subjugação para descentrarmos os imperativos dos padrões impostos pela heterossexualidade compulsória:

\begin{abstract}
Michel Foucault, em História da Sexualidade, volume I, "A vontade de saber", afirma que a pessoa pode sobreviver, desde que não apareça, ou seja, desde que se coadune a esse parâmetro. As mulheres, os negros e os homossexuais terão direitos desde que se comportem e aceitem todas as visões do mundo, as posturas e as condutas dos homens brancos heterossexuais. Essa é a visão simples do princípio da igualdade, limitado ao princípio da antidiscriminação. Trata-se, evidentemente, de um avanço, mas precisamos ir além e interpretar o princípio da igualdade também como princípio da anti-subjugação, que se relaciona com o da igual-
\end{abstract}

9 Isso se pensarmos que o conceito de humanidade deve estar associado à noção de cidadania, com seus direitos e garantias fundamentais. 
dade e o da dignidade da pessoa humana, estabelecendo que se deve conferir igual reconhecimento, igual valor às pessoas, independentemente de sua condição, o que difere totalmente de se eleger um padrão ao qual os dessemelhantes devam ser equiparados (RIOS, 2018, p. 157, grifos nossos).

Os destaques por nós feitos na citação de Rios sinalizam como os vazios legislativos ou a existência de legislações só podem se tornar potentes em suas transformações se a igualdade como princípio democrático prescinde de modelos/padrões a serem seguidos. Esse é um dos principais epistemocídios que nos institui: a dialética como dualidade reificadora da unidade ao invés da multiplicidade (VIVEIROS DE CASTRO, 2015). Afinal, para essa dualidade da unidade: é não é o que não é, é. Ei-la como unidade e despotência, eis o quanto se escorregam direitos e cidadania neste país à custa de comparações tecidas com o padrão do branco, heterossexual e com vida sedentária garantida pelas "posses" e escrituras de propriedade.

Assim, claro está que as questões presentes no PL 6583/2013, bem como seus respectivos impasses, não são novas. Pelo contrário, encontram ecos em uma série de articulações por parte de certos segmentos conservadores da sociedade brasileira em torno da manutenção de um conjunto de práticas e valores considerados tradicionais e, consequentemente, pela luta em torno da manutenção de privilégios daí advindos. Tais segmentos, reivindicando a preservação de determinados valores, frutos de uma perspectiva judaico-cristã heteronormativa, tendem a considerar uma série de mudanças ocorridas na sociedade brasileira como uma espécie de ameaça.

Nesse sentido, não são poucas as afirmações de que "a família está ameaçada", "a sociedade vive uma crise de valores" e que existem segmentos sociais que são "inimigos da moral e dos bons costumes" e, portanto, da "família", esta última compreendida como célula mater”, instituição estabelecida por Deus e, como tal, princípio vital do mundo social. Assim, qualquer arranjo que fuja ao modelo hegemônico tende a ser rechaçado e combatido.

Anteriormente ao PL 6583/2013, já em 2007, o deputado Sérgio Barradas Carneiro (PT/BA) havia apresentado o PL 2285 (CÂMARA DOS DEPUTADOS, 2018b). Em suas 45 páginas, o projeto tinha como objetivo, conforme seu Art. 10: "regula[r] os direitos e deveres no âmbito das entidades familiares" (CÂMARA DOS DEPUTADOS, 2018b). Se por um lado também se apresentava a busca pela definição de família e, portanto, sua institucionalização, por outro, havia uma compreensão mais alargada de tal conceito, citando-se explicitamente as uniões homoafetivas. É o que podemos constatar em seu Art. 68: "é reconhecida como entidade familiar a união entre duas pessoas de mesmo sexo, que mantenham convivência pública, contínua, duradoura, com objetivo de constituição de família, aplicando-se, no que couber, as regras concernentes à união estável” (CÂMARA DOS DEPUTADOS, 2018b). Contudo, tal projeto, por falta de apoio político na Câmara, contando com uma adesão inexpressiva de políticos progressistas e pela ampla mobilização de conservadores, acabou sendo engavetado.

Esse movimento conservador, que tem sido levado a cabo principalmente pela bancada evangélica (embora também conte com políticos católicos atrelados principalmente à Renovação Carismática Católica - RCC, é o caso dos deputados Eros Biondini, do PROS/MG, e Flávio Augusto da Silva, do PSB/SP), tem como base, conforme já apontado, uma definição cristã e naturalizada tanto da família quanto de práticas sociais. Tais iniciativas contrárias ao reconhecimento e à garantia de uma cidadania plena, principalmente para LGBTs, tem construído uma série de investidas contra alguns direitos historicamente reconhecidos: 
como o casamento civil entre pessoas do mesmo sexo (reconhecido pelo Supremo Tribunal Federal em 2011) e a adoção de crianças por casais homoafetivos.

Com relação a este último ponto, cabe ressaltar o projeto de lei apresentado pelo deputado Ronaldo Fonseca (PROS/DF) que visa alterar o Estatuto da Criança e Adolescente (ECA) no que se refere à definição de família. Na prática, tal redefinição, baseada em princípios cristãos, teria como resultado a impossibilidade de crianças serem adotadas por casais LGBTs. Se, conforme dados apresentados em 2015 (G1, 2005), 87\% dos deputados que compõem a Câmara Federal são assumidamente cristãos, há razões para nos perguntarmos em que medida a garantia de um estado laico, que reconhece direitos e garantias fundamentais que muitas vezes estão na contramão de padrões discursivos religiosos, não estaria sendo ameaçado.

Nesse cenário conservador e fundamentalista, não apenas o reconhecimento de novos arranjos familiares é colocado em xeque mais uma vez, mas também e, ao mesmo tempo, outras pautas historicamente levantadas por amplos setores da sociedade brasileira, tais como a luta pela descriminalização do aborto (no âmbito dos direitos sexuais e reprodutivos), pela criminalização da homofobia e pela descriminalização da maconha (seja para fins terapêuticos ou para uso recreativo).

\section{Considerações finais}

A partir do exposto, podemos dizer que, se por um lado nos deparamos com um discurso que é controlado, selecionado, organizado e distribuído (FOUCAULT, 1999), por outro observamos uma verdadeira luta, uma autêntica resistência que dispara re(existências). Enquanto tática biopolítica, essa discursividade que luta pela definição legítima e que opera segundo a lógica da afirmação-exclusão tem no campo jurídico-legal seu lócus de atuação por excelência (embora não exclusivo). Contudo, essas táticas são ambíguas e não estão dadas de antemão. Portanto, ao mesmo tempo em que operam em uma tentativa de ocultação e dissimulação, deixam escapar seus limites, contradições e arbitrariedades, evidenciando assim seu caráter performativo.

É o que se revela quando da tramitação do PL 6583/2013 na Câmara, mais especificamente quando dois deputados se manifestaram contrários aos pressupostos do projeto. Acompanhemos o caso dos deputados Glauber Braga (PSolRJ) e de Erika Kokay (PT-DF). Conforme Glauber, "[...] o substitutivo é discriminatório e preconceituoso e retira direitos de milhões de brasileiros que não se enquadram no conceito de família aprovado" (CÂMARA DOS DEPUTADOS, 2018c, s/p). Já a deputada Erika Kokay ponderou: "[...] concepções religiosas não podem solapar o direito à informação" (CÂMARA DOS DEPUTADOS, 2018c, s/p). Observa-se, então, um tensionamento constantemente agenciado e relacionalmente negociado. Se de um lado impera no projeto uma lógica binária, essencializada e hierárquica das relações familiares, por outro, os diferentes sujeitos em cena, bem como os distintos interesses e desejos mobilizados, acabam por apontar para as possibilidades de negociação, transformação e questionamento.

No mundo contemporâneo, não apenas encontramos arranjos que não correspondem ao padrão da família tradicional, como também formas de vinculação que escapam aos projetos de institucionalização da vida. Ademais, verifica-se uma série de problemas no seio de uma família convencional que dão mostras de que família (pensada como constituída por um homem, uma mulher e 
seus filhos) não é sinônimo de sucesso, felicidade e perfeição. Não apenas tal ideal de família perfeita, ou conforme os termos do próprio PL, "uma família equilibrada" é inexistente, como inalcançável. Precisamos, pois, considerar que as discursividades presentes no projeto apontam mais uma vez para as arbitrariedades das técnicas de governança, sejam elas quais forem, e para a necessidade de constituição de modelos alternativos.

Judith Butler (2003b), ao refletir sobre a reivindicação do movimento homossexual em torno do reconhecimento de suas uniões estáveis, problematiza(va) em que medida o movimento homossexual não estaria submetendo-se aos mesmos modelos aos quais historicamente tem buscado enfrentar e a se contrapor $^{10}$. Para a autora, não podemos ignorar a existência de "[...] relações de parentesco que não se enquadram no modelo de família nuclear e que se baseiam em relações biológicas e não biológicas, ultrapassando o alcance das concepções jurídicas" (BUTLER, 2003b, p. 221).

Tais questões nos confrontam com alguns dilemas. Se, enquanto um aparato de governamentalidade, o Estatuto da Família não é outra coisa senão um mecanismo de regulação de grupos, corpos, de práticas, de sujeitos (OLIVEIRA, DUQUE, 2016), como não perdermos de vista o caráter ambíguo e instável das táticas e estratégias de governança e a potência contestatória das práticas dissidentes formadas no interior dos regimes biopolíticos? Afinal, [as práticas dissidentes] "criam oportunidades críticas de expor os limites e os objetivos reguladores desse campo de inteligibilidade e, consequentemente, de disseminar, nos próprios termos dessa matriz de inteligibilidade, matrizes rivais e subversivas de desordem de gênero" (Butler, 2003a, p. 44).

Assim, se a luta pelo reconhecimento no estatuto da família não deve ser entendida como um mero ato de supervalorização de um dispositivo biopolítico; nem como uma prática que simplesmente contribui com a legitimação, manutenção e funcionamento de um modelo de cidadania de viés institucionalistanormativo; muito menos como uma estratégia que reitera possíveis lógicas de uma inclusão-conformativa, ao mesmo tempo precisamos permanentemente nos questionar sobre qual tipo de práticas dissidentes temos produzido no interior dos regimes biopolíticos. Deste modo, vemos como oportuna e urgente tanto a intensificação das lutas pela consolidação dos direitos socialmente instituídos, como também, e concomitantemente, a necessidade de criação e proliferação de outras formas de acessar direitos e viver, experimentar a cidadania.

Talvez esse seja o grande nó da questão.

Recebido em 28 de abril de 2018.

Aprovado em 24 de setembro de 2018.

${ }_{10} \mathrm{O}$ que antes sinalizamos com Rios (2018), que aponta ser despotente a igualdade se alinhar com o princípio da antidiscriminação. 


\section{Referências}

ALMEIDA, Ronaldo de. A onda quebrada - evangélicos e conservadorismo. Cadernos Pagu, Campinas, 50, 2017, e175001.

BECKER, Simone; OLIVEIRA, Esmael Alves. Educação e direitos para (in) humanos? Desafios e reflexões sobre os dilemas de LGBT'S perante o discurso jurídico brasileiro. Revista Tempos e Espaços em Educação, São Cristóvão/SE, 9 (19): 163-180, mai./ago. 2016.

BECKER, Simone; OLIVEIRA, Esmael Alves de; CAMPOS, Marcelo Siqueira. Guarani-Kaiowá: "Onde fala a bala, cala a fala". Brasil Debate, Site Brasil Debate, 22 jun. 2016. Disponível em: http://brasildebate.com.br/guarani-kaiowaonde-fala-a-bala-cala-a-fala. Acesso em: 18 ago. 2018.

BECKER, Simone; LEMES, Hisadora B. G. Vidas vivas inviáveis: Etnografia sobre os homicídios de travestis no Tribunal de Justiça de Mato Grosso do Sul. Revista Ártemis, 18: 184-198, 2014.

BUTLER, Judith. Quadros de Guerra: quando a vida é passível de luto? Rio de Janeiro, Civilização Brasileira, 2015.

BUTLER, Judith. Le pouvoir des mots. Politique du performatif. Paris: Éditions Amsterdam, 2004.

BUTLER, Judith. Problemas de gênero: feminismo e subversão da identidade. Rio de Janeiro: Civilização, 2003a.

BUTLER, Judith. O parentesco é sempre tido como heterossexual? Cadernos Pagu, Campinas, NEG/UNICAMP, 21: 219-260, 2003b.

CHECA, Maria Eduarda Parizan. O silêncio como discurso: o Projeto de Lei "Escola sem Partido" e a invisibilidade da juventude LGBT na lógica da mordaça: relatório final de pesquisa de Iniciação Científica. Mimeo, Campo Grande: UCDB; CNPq, 2017.

CÂMARA DOS DEPUTADOS. PROJETO DE LEI 6583/2013. Disponível em: http://www.camara.gov.br/proposicoesWeb/prop_mostrarintegra?codteor $=115$ 9761\&filename $=P L+6583 / 2013$. Acesso em: 01 jul 2018a.

CÂMARA DOS DEPUTADOS. PROJETO DE LEI 2285/2007. Disponível em: http://www.camara.gov.br/proposicoesWeb/prop_mostrarintegra;jsessionid=1 90DB183367ACB3AED022ACBA22F8C12.proposicoesWeb1? codteor $=517043 \& f$ ilename $=$ PL+2285/2007. Acesso em: 01 jul 2018b.

CÂMARA DOS DEPUTADOS. Portal Câmara dos Deputados, 08/10/2015. Disponível em: http://www2.camara.leg.br/camaranoticias/noticias/DIREITOS-HUMANOS/497879-CAMARA-APROVA-ESTATUTO-DA-FAMILIA-FORMADA-A-PARTIR-DA-UNIAO-DE-HOMEM-E-MULHER.html. Acesso em: 1 de julho de 2018.

DESPENTES, Virginie. Teoria King-Kong. São Paulo: N-1 edições, 2013.

FASSIN, Didier. Another politics of life is possible. Theory, Culture \& Society, 26 (5): 44-60, 2009.

FERREIRA, Camila Camargo. A "ideologia de gênero" como uma prática discursiva tagarela de silenciamento: uma análise genealógica do projeto de lei 
escola sem partido. 2018. Dissertação (Mestrado) - Programa de PósGraduação em Sociologia - Universidade Federal da Grande Dourados, Dourados, MS.

FOUCAULT, Michel. Segurança, território população. São Paulo: Martins Fontes, 2008.

FOUCAULT, Michel. História da Sexualidade: a vontade de saber. 18. ed. Rio de Janeiro: Graal, 2007.

FOUCAULT, Michel. "A governamentalidade”. In: FOUCAULT, Michel (Org.). Microfísica do poder. 24 ed. Rio de Janeiro: Graal, 2007a.

FOUCAULT, Michel. A ordem do discurso. São Paulo: Loyola, 1999.

FOUCAULT, Michel. "O sujeito e o poder". In: RABINOW, Paul; DREYFUS, Hubert (Orgs.). Michel Foucault: uma trajetória filosófica para além do estruturalismo. Rio de Janeiro: Forense Universitária, 1995.

GUATTARI, Félix. A revolução molecular. Pulsações políticas do desejo. 3. ed. SP: Brasiliense, 1985.

G1 - Portal de notícias. $71 \%$ dos futuros deputados se dizem católicos e 16\%, evangélicos. Disponível em: http://g1.globo.com/politica/noticia/2015/01/71dos-futuros-deputados-se-dizem-catolicos-e-16-evangelicos.html. Acesso em: 01 jul 18.

LAQUEUR, Thomas. Inventando o sexo: corpo e gênero dos gregos a Freud. Rio de Janeiro: Relume Dumará, 2001.

MACEDO, Rayane Bartolini. Debaixo da terra: uma genealogia cartográfica acerca dos discursos que permeiam as tessituras rizomáticas da PEC 215. 2017. Dissertação (Mestrado em Sociologia) - Universidade Federal da Grande Dourados, Dourados/MS, 2017.

MBEMBE, Achille. Necropolítica. Revista do PPGAV/EBA/UFRJ, Rio de Janeiro, 32: 23-151, 2006.

MELLO, Luiz. Familismo (anti) homossexual e regulação da cidadania no Brasil. Revista Estudos Feministas, Florianópolis, 14 (2): 497-508, maio-ago. 2006.

MISKOLCI, Richard. Estética da existência e pânico moral. In: RAGO, M. VeigaNeto (Org.). Figuras de Foucault. 2. ed. Belo Horizonte: Autêntica, 2008.

OLIVEIRA, Esmael Alves de; DUQUE, Tiago. Políticas do corpo, políticas da vida: uma análise sobre o estatuto da família no Brasil. Revista Nanduty, UFGD, 4 (5): 132-153, 2016.

PERES, Milena Cristina Carneiro; SOARES, Suane Felippe; DIAS, Maria Clara. Dossiê sobre lesbocídio no Brasil: de 2014 até 2017. Rio de Janeiro: Livros Ilimitados, 2018.

PRECIADO, Paul Beatriz. Testo Junkie: Sexo, drogas e biopolítica na era farmacopornográfica. São Paulo: N-1 edições, 2018.

RIOS, Roger Raupp. A discriminação por gênero e por orientação sexual. Disponível em: http://www.clam.org.br/bibliotecadigital/uploads/publicacoes/ 693_609_riosroger.pdf. Acesso em: 30 ago. 2018.

ROLNIK, Suely. Esferas da insurreição: notas para uma vida não cafetinada. São Paulo: N-1 edições, 2018. 
TARNOVSKI, Flávio L. Questões sobre o debate social e político atual sobre família. Informativo especial da Associação Brasileira de Antropologia - Balanços parciais a partir de perspectivas antropológicas, fev. 2016, p. 01-04.

VIVEIROS DE CASTRO, Eduardo. Metafísicas Canibais. São Paulo: CosacNaify \& N-1 edições, 2015. 